\title{
1. Resilience, crisis and innovation dynamics: emerging challenges
}

Tüzin Baycan and Hugo Pinto

\section{RESILIENCE, CRISIS AND INNOVATION DYNAMICS}

The concept of resilience has gained particular relevance to the understanding of socio-economic systems since its expansion in ecology studies. It has been widely used in a variety of areas centered around flexible adaptation, usually in a socio-economic or ecological environment where risk, uncertainty, unpredictability and turbulence are recurrent. The history of resilience as a concept is closely related to the emergence of system's approach and new ecological ideas in the late 1960s (Davoudi et al., 2012). At that time, a new awareness of environmental degradation was translated into social movements and turmoil that questioned industrial paradigms and Western hegemony. The neoclassical economic principle that growth can exist without regard for resource limitations began to inspire concerns among both intellectuals and the general public. The most often cited resilience-framework, Holling's resilience theory (Holling, 2010), was an explicit critique of the departure of 1970s industrial management practices from the idea that a system stabilizes around a single equilibrium. The concept was described at the time as the ability of a system to maintain its constitutive relationships and properties in the face of disturbances. Resilience related research began to recognize that systems may move through multiple equilibria.

The growing interest in explaining the causes and consequences of the recent financial and economic crisis gave relevance to the study of resilience. Since 2007, several regions in the world have faced different types of socio-economic impacts of varying magnitudes as a result of the crisis. Some territories were not prepared for these external shocks and entered into economic downturns, with more unemployment and loss of productive capacity, while others were able, through the reconfiguration of their economic structures and the improvement of their innovative capacities, to create new development trajectories. The notion of resilience has gained huge notoriety in the last few years and was imported by many 
sub-fields of social sciences and the humanities. In this context, resilience has frequently emerged in Regional Science as an explanation of how territorial socio-economic systems adapt, successfully or not, to negative events. Rooted in evolutionary economics and evolutionary economic geography, the term regional resilience has become highly popular in both research and policy-making because of its association with regional adaptation processes.

While resilience usually refers to the capacity of individuals, organizations and systems to respond to shocks, the evolutionary approach has a slightly different perspective which has quite a profound impact on the concept. Evolutionary resilience points to the capacity of a region to both sustain long-term development and to respond positively to short-term shocks. In this approach, regional resilience is conceptualized not just as the ability of a region to accommodate shocks, as is common in the literature, but is extended to the ability of a region to reconfigure socio-economic and institutional structures to develop new growth paths (Boschma, 2015). Or, as Simmie and Martin (2010: 28) see it: "as 'adaptive ability' since it is the differential ability of a region's or locality's firms to adapt to changes and shocks in the competitive, market, technological, policy and related conditions that the evolutionary dynamics and trajectories of that regional or local economy over time." This approach is still in a very early stage of development. Nonetheless, the idea has drawn quite a degree of attention from regional scientists focused on presenting possible solutions to the impacts that crises and disasters have on contemporary society.

Innovation dynamics is seen as the critical dimension in the comprehension of regional resilience. For many authors the ability of regional economies to reconfigure themselves is dependent on innovation (Christopherson, Michie, and Tyler, 2010). Thus innovation is the means to overcome economic crisis. Regional resilience studies underline the importance of systemic innovation to the adaptive capacity of territories. Innovation systems can play a major role in overcoming the negative effects of shocks, as they combine the capacities of a variety of actors, from corporate and independent $\mathrm{R} \& \mathrm{D}$ centers to educational organizations at different levels, industrial associations, firms, and governance bodies, in the pursuit of socio-economic vitality.

Many authors emphasize the relevance of strong innovation systems to resilience (Fromhold-Eisebith, 2015; or Pinto and Pereira, Chapter 3 in this volume). From this perspective, innovation systems can be an interesting analytical unit for the understanding of resilience through their exploration of the structural characteristics of the innovation networks within territories, linkages among actors, their density and role, and institutional architectures. The difficulties and advantages of regions are 
related to the structural configuration of networks (Ter Wal and Boschma, 2008). Regions with connected, diverse knowledge networks can not only recover more rapidly from shocks but also create growth in a sustainable way. The internal structure of knowledge networks in a region, as well as their openness to the outside world, matter for regional resilience because they impact the sensitivity of regions to shocks and improve the capacity to develop new trajectories (Crespo, Suire, and Vicente, 2014). Proximity plays an important role in the innovation networks (Boschma, 2005). Different dimensions of proximity - geographical, cognitive, organizational, social, institutional - help to reduce uncertainty and solve problems of coordination, and thus facilitate interactive learning and innovation. But there are drawbacks to excessive proximity for innovation, especially regarding lock-in effects or a lack of openness and flexibility.

In parallel with this aggregated vision of regional resilience, the impacts of crisis on innovation actors are worth attention. The capacity of each innovation system depends largely on interactions between "public science" and the demand and production of firms. It is crucial to understand the consequences of economic turbulence in the innovation dynamics at the firm, research, and policy levels.

Universities and other public research organizations contribute to firms' performance in many and varied ways (Pinto and Esquinas, 2013), from human-resources training, use of university facilities, contract research, consultancy, public-private partnerships, collaborative projects and exchange of personnel, among others. But university-firm interactions depend on a myriad of conditions. Not only is there a difference in goals and institutional frameworks, with one oriented toward material gain while the other focuses on the principles of open and free knowledge, but also a difference in the way in which they operate. Universities, in particular European universities, are public entities that function on the basis of open communication of their findings and results. On the one hand, the university's interest is stimulated by the potential of the commercialization of knowledge and the economic valorization of research results (Baycan, 2013; Baycan and Stough 2013). On the other hand, firms ultimately work towards the private appropriation of knowledge and the competitive advantages that such knowledge may provide to them. The firm's absorptive capacity, related with the qualification of employees and dedicated research departments, is the main mechanism for more meaningful interaction with universities. Small and medium enterprises (SME), which have fewer resources, thus face more difficulties in innovating. They have to find new ways of overcoming their limitations with open innovation strategies and external sources of knowledge, namely knowledge-intensive business services. This matters greatly to peripheral regions, as they are dominated 
by SMEs which often specialize in traditional sectors of activity (Pinto, Esquinas, and Uyarra, 2015).

It is with no surprise that the study of regional resilience must consider the relevance of innovation systems, knowledge networks and the role that innovation actors play to create new possibilities for preparing for and adapting to not only present shocks but also problems that may arise in the future.

\section{ORGANIZATION OF THE BOOK}

This volume brings together regional scientists interested in the study of crisis and innovation dynamics. Resilience here is used as a bridging notion to connect different types of theoretical and empirical approaches to the comprehension of the impacts of economic turbulence at the system and actor levels. The volume helps to rethink how regional resilience can be improved and how the social aspects of vulnerability, resilience and innovation can be integrated. It also addresses recent theories and concepts related to research on crisis, resilience and innovation dynamics, providing a valuable overview and introduction to this rapidly emerging field for academics, policy-makers, researchers and students who share a common interest in and commitment to resilience and innovation.

The volume consists of three main parts. Part II, titled "Innovation, Crisis and Resilience," consists of six chapters that intend to directly connect innovation, the economic slowdown and the concept of resilience.

Chapter 2 by Tüzin Baycan and Berna Sezen Özen focuses on the effects of the global economic crisis on the innovation performance of EU countries. The chapter investigates the relationship between the economic crisis and innovation performance while addressing the changes in the indicators of the European Innovation Scoreboard Index after the global economic crisis in 2008. Focusing on these changes over the last ten years, the chapter compares and evaluates innovation performance of EU countries and highlights which countries were more resilient in dealing with the economic crisis.

Chapter 3 by Hugo Pinto and Tiago Santos Pereira addresses the resilience of innovation systems under economic turbulence. It debates the notion of resilience as an adaptive capacity that contributes to overcome negative effects of internal and external shocks, creating growth trajectories in different socio-economic systems. The chapter emphasizes the need to delimit the system to be analyzed and suggests that the "regional innovation system" is a central unit of analysis in the study of science, technology and innovation resilience. The chapter also suggests that an analysis of systemic failures is crucial for a deeper understanding of internal fragilities. 
Chapter 4 by Magdolna Benke, Klára Czimre, Katalin R. Forray, Tamás Kozma, Sándor Márton, and Károly Teperics focuses on the resilience of learning regions in Hungary and reconsiders the results of the LeaRn research project ('Learning Regions in Hungary: From Theory to Reality'). The study presents a statistical examination of the spatial centers of learning and identifies potential learning regions in Hungary. The complex indicator and map of learning regions suggest important messages about the conditions and potentials of the evolution of learning in Hungary. The main hypothesis of the study is that learning regions in Hungary have the potential to become resilient regions if they stimulate geographic, cultural and social proximity among actors. A comparison of learning patterns and socio-economic indicators allows for the conclusion that Hungarian regions which are more open to learning have better economic performances and higher well-being.

Chapter 5 by Valeria Szitasiova, Miroslav Sipikal, and Monika Siserova deals with resilience in the context of innovation activity in the regions of the Slovak Republic. As innovation in Slovakia is, as in the majority of EU member states, overwhelmingly supported by the resources of the European Union, this chapter analyzes innovation support in terms of resilience to upcoming trends of economic development. The analysis identifies a moderate direct relationship between resilience and innovation activity in Slovak regions. The key findings suggest that more resilient regions were bolstered by a higher amount of support and reacted to the crisis better than non-resilient districts.

Chapter 6 by Masagus M. Ridhwan and Pakasa Bary attempts to examine the effects of macroeconomic shocks across Indonesian regions. The study develops structural macroeconomic models representing demandside output, supply-side output, monetary and fiscal aspects, and prices in each region. The results of the study suggest systematic differential responses to common shocks on both regional output and inflation, which may well be related to the individual regional economic structures and its specific characteristics.

Chapter 7 by Philip Cooke focuses on transversality, resilience and innovation. The chapter demonstrates that superior regional innovation policymaking is based on non-linear, lateral and interactive governance. It begins by introducing basic concepts of resilience, modeled on its original application in understanding the behavior of ecosystems under stress, translated into a more suitable context of economic geography. There follows a worked, theoretically derived application of resilience theory to qualitative case analyses of responses to resilience shock by regions in Portugal. Here, severe economic crisis was the test of resilience. Innovative adaptability, emphasizing transversality, not particularity, tended to predominate. In its 
conclusion, it is shown how, by exploration of regional and inter-regional transversality, these regions avoided the demonstrably reckless specialization advocated by a global controller (EU). This was achieved in the face of austerity measures imposed by the EU and the national government in response to the global financial crash of 2008 as it affected the fate of their regional design of research and innovations strategies for smart specialization (RIS3).

Part III, titled "Labor Markets, Employment and Resilience," consists of five chapters and explores the effects of the crises in the labor market and on employment dynamics.

The first chapter of this part, Chapter 8 by Benjamin Jara and Alessandra Faggian, examines and proposes an empirical application to understand specific aspects of labor market resilience after a disaster. Different types of re-orientation are defined and estimated using data regarding workers in regions affected by an earthquake. Results indicate that the probability of employment was the most significant impact of the disaster, while industry switching and wage growth are affected by neither the earthquake nor place-specific characteristics. Positive and negative convergence effects are observed in the poorest and richest regions, respectively. The results show heterogeneity among industries, although these effects are not essentially different from conditions in pre-disaster years.

Chapter 9 by A. Suut Doğruel, Fatma Doğruel, and Yasemin Özerkek investigates external shocks and regional economic performance in Turkey. This chapter, which focuses on unemployment in Turkey, has two main goals: first, to identify the determinants of regional unemployment, and, second, to scrutinize the effects of external shocks on regional variations in economic performance in Turkey. Migration is assumed to be the main source of the variations in the regional labor supply. The study defines two types of structural changes at the regional level: changes in the sectoral composition and dispersion in employment growth across sectors. Regional unemployment is determined by supply and demand indicators. The chapter defines two exogenous shocks: the 2008 crisis and migration issues at the regional level. The character of the 2008 crisis was global, without any local dimension, and its effects can be defined as completely exogenous. Migration, on the other hand, could have been affected partly by the regional factors. Therefore, it may be assumed that this shock was partially exogenous. Defining regions as flexible or rigid against these shocks, the results reveal that adjustment potential is higher in the regions with a relatively simpler economic structure.

Chapter 10 by Yannis Psycharis, Dimitris Kallioras, and Panagiotis Pantazis provides empirical evidence regarding the impact of economic crisis on employment changes in the Greek regions between 2008 and 2012. 
With the application of trade-adjusted shift-share analysis, the chapter presents evidence of whether openness and trade have affected the resilience of regions. Results indicate that economic crisis has asymmetrically impacted regional employment losses, leading to a widening of regional employment disparities. The construction and manufacturing sectors were hit severely by the crisis. Agriculture constituted a resilient sector, while knowledge- and technology-intensive sectors were also more resilient to crisis. The less well-off regions dependent on more traditional sectors proved to be more resilient. However, trade relations and openness were stabilizers to the shocks of the economic downturn.

Chapter 11 by Barbara Martini, addresses resilience, reorientation and variety, and analyzes the Italian provinces after the 2007 economic shock. The chapter highlights the elements that make an area able to withstand a shock. The results highlight that re-orientation and variety can contribute to the creation of resilience at a provincial level.

Chapter 12 by Francisco Javier Ortega-Colomer, Elias Pekkola, and Tuomo Heinonen addresses the role of engineering education in industrial transition. The chapter focuses on a comparison of two different geographical settings where higher education institutions have played an important role in the modernization of industrial manufacturers. Both settings - the cities of Alcoy (Spain) and Tampere (Finland) - are historically important centers of industry which showed a downturn in production but now aim to be innovation hubs in their respective areas. A historical analysis, based on secondary data, is presented as a means to understand the recent resilience and evolution of both regions, in terms of their capacity for facing societal challenges such as the growth of inequalities, the creation of new related industries, the globalization process and the financial crisis, in different periods. An emphasis is placed on the complex relationships among geographical, institutional and individual dynamics that enable the commissioning of heterogeneous innovation processes for resilience.

The last part of the volume, Part IV, titled "Clusters, Industrial Dynamics and Resilience," consists of five chapters and highlights the importance of certain characteristics in the economic fabric of a region, such as the emergence of clusters and other local production systems with regard to regional resilience.

The first chapter of this part, Chapter 13 by Roger R. Stough, investigates learning regions, clusters, and resilience. The chapter evaluates a series of cluster and regional dynamics studies to provide evidence that industrial clusters evolve somewhat regularly through a series of stages. This stage or cycle theory views clusters as proceeding from initiation to some asymptotic limit with subsequent decline and/or rejuvenation. The capacity of a cluster to rejuvenate itself can be understood as its resilience. 
Clusters have a geographic locus as well as an extra local network component and are viewed from a systems perspective. The chapter examines, on the basis of several case studies, the process or lack thereof that lagging or declining clusters use to reinvent themselves or fail. An examination of the case studies reveals five general types of histories that clusters, their regions, and their urban contexts appear to experience. From this research a resilience typology for cluster dynamics is proposed.

Chapter 14 by Maria Estela Ferreira illustrates the resilience of the footwear industry in the North of Portugal. This industry acts as a cluster and is located in a number of towns within a $50 \mathrm{~km}$ radius of Oporto. This cluster is responsible for more than 90 percent of Portuguese footwear exports. During the last 30 years, among other difficulties, the main shock the industry had to face was the entry of China to the World Trade Organization in 2001, which resulted in the delocalization of many of the foreign footwear companies operating in Portugal. The industry survived and surpassed this shock thanks to the action of entrepreneurs, together with a strong and active association which provided management and technical support and strengthened links among such entrepreneurs, stimulating coordinated actions, in partnership with a technological center and with universities. The chapter suggests that the Portuguese footwear exports are close to the level they would have reached if China had not joined the WTO.

Chapter 15 by Ana Santos Bravo analyzes the role of innovation and technology transfer in firms, particularly in the bio-pharmaceutical cluster located in Oeiras, a municipality of Lisbon. Government and local policies towards the promotion and development of business and technologies are important factors in an increase in foreign investment, productivity and business competitiveness. Technological-based industries, including pharmaceuticals and software, have grown rapidly in the last two decades in Oeiras, which has also attracted some scientific research centers and institutes that ensure the transfer of knowledge to economic activities.

Chapter 16 by Mete Başar Baypınar addresses the response of the software industry in Turkey to policy change and argues that knowledgeintensive sectors are of significant interest for both regional planners and policy-makers. Knowledge-intensive sectors promise better jobs and economic growth. However, while some clusters dominate and persist, others do not have this capacity to maintain their competitiveness. The resilience of this industry seems highly dependent on changes in the global industrial structure, economic and policy shocks, and state support. The study suggests that policy-makers should not adopt generic strategies but focus on well-defined targets and unique strategies regarding the life-cycle of a specific industry. 
The last chapter of the volume, Chapter 17 by Roberta Comunian and Lauren England investigates the resilience of creative clusters. The chapter connects the emergent literature on resilience and evolutionary perspectives in economic geography with the current knowledge and understanding of creative clusters. Focusing on the crafts sector in the UK, the concept of resilience is explored as a conceptual framework to explain and explore the shift from industrial to post-industrial economies. The focus of the chapter is on the resilience of knowledge - and the role of networks in supporting this resilience in the shift between industrial production and creative craftsmanship. The chapter, using three case studies of three industrial clusters - jewellery in Birmingham, pottery in Staffordshire and glass in Stourbridge - finds strong industrial development and mass-production patterns which, following the post-industrial decline and new dynamics of global outsourcing, have diminished and almost disappeared. Many industries have disappeared due to economic decline; craftsmanship has been reinvented and strengthened in newly emerging creative productions.

\section{EMERGING CHALLENGES}

Resilience, as a concept, is evolving from the mere idea of dealing with shocks to a system to long-term planning mechanisms of coping with such situations. Regional science is trying to go beyond a classical engineering view of resilience as a mechanical return to the previous equilibrium after an exogenous and external shock. It is attempting to capture the endogenous mechanisms of adaptability, viewed as the ability of actors and their social agency to anticipate, evolve, and adapt to disturbances and cyclic variations. Resilience is seen as a bouncing-forward ability of a system to undergo anticipatory or reactionary reorganization to minimize the impact of destabilizing shock, creating new growth trajectories.

There are many challenges to the utilization of a satisfactory notion of resilience in Regional Science (Boschma, 2015). An overall evaluation of this volume highlights emerging challenges in the understanding of regional resilience. The first challenge is the need to integrate the two temporal dimensions of resilience: the short-term capacity to absorb shocks and the long-term capacity to develop new growth paths. Even if it is underlined by the majority of studies that what is in discussion is an evolutionary approach to resilience, the need for a return to equilibrium and long-term trajectories remains implicit in most analyses. The second challenge is the lack of understanding of how regions develop new growth paths, as there is limited attention of what determines their long-term adaptation. Empirical studies usually make use of relative short-term 
perspectives even when it is clear that the effects persist in time and often take a long period to dissipate. Future research should try to include in its analyses the evaluation of longer trajectories. Third, the literature still associates adaptability with new growth paths that are detached from their past. Past resources and capabilities contribute to shape new growth paths. History matters for the construction of new futures. We need to integrate carefully the study of the historical context when analyzing specific territories' resilience. Fourth, regional resilience needs to be rethought as the capacity of regions to overcome the idea of a trade-off between adaptability and adaptation. Different characteristics of adaptation and adaptability may explain how regions create more resilience. Finally, evolutionary regional resilience needs to account for the complex and multidimensional nature of resilience, as regions are groups of individuals, organizations, industries, networks and institutions, each with their own processes of path dependence and tensions between adaptation and adaptability. This encompasses an additional effort of research: to look for the attributes that characterize resilience at the system, network and organizational levels.

All in all, this volume offers a wealth of refreshing studies with great value for academia, industry and government and suggests a set of challenges from different regional and structural perspectives that may help to consolidate the research about resilience in Regional Science.

\section{REFERENCES}

Baycan, T. (ed.) (2013) Knowledge Commercialization and Valorization in Regional Economic Development. Cheltenham, UK and Northampton, MA, USA: Edward Elgar Publishing.

Baycan, T., and Stough, R.R. (2013) Bridging knowledge to commercialization: the good, the bad, and the challenging, Annals of Regional Science, 50(2): 367-405.

Boschma, R. (2005) Proximity and innovation: a critical assessment, Regional Studies, 39(1): 61-74.

Boschma, R. (2015) Towards an evolutionary perspective on regional resilience, Regional Studies, 49(5): 733-751.

Christopherson, S., Michie, J., and Tyler, P. (2010) Regional resilience: theoretical and empirical perspectives, Cambridge Journal of Regions, Economy and Society, 3(1): 3-10.

Crespo, J., Suire, R., and Vicente, J. (2014) Lock-in or lock-out? How structural properties of knowledge networks affect regional resilience, Journal of Economic Geography, 14(1): 199-219.

Davoudi, S., Shaw, K., Haider, L.J., Quinlan, A.E., Peterson, G.D., Wilkinson, C., Fünfgeld, H., McEvoy, D. (2012) Resilience: a bridging concept or a dead end? "Reframing" resilience: challenges for planning theory and practice interacting traps: resilience assessment of a pasture management system in Northern 
Afghanistan urban resilience: what does it mean in planning, Planning Theory \& Practice, 13(2): 299-333.

Fromhold-Eisebith, M. (2015) Sectoral resilience: conceptualizing industry-specific spatial patterns of interactive crisis adjustment, European Planning Studies, 23(9): 1675-1694.

Holling, C.S. (2010) The Resilience of Terrestrial Ecosystems, in L.H. Gunderson, C.R. Allen, and C.S. Holling (eds) Foundations of Ecological Resilience, Washington, DC: Island Press, 67-119.

Pinto, H., and Esquinas, M.F. (2013) Exploring Knowledge-Transfer Dynamics in a South European region: Breadth, Intensity and Informality of UniversityIndustry Interactions in Andalusia, in T. Baycan, and R. Stough (eds) Knowledge Commercialization and Valorization, Cheltenham, UK and Northampton, MA, USA: Edward Elgar Publishing, 209-237.

Pinto, H., Esquinas M.F., and Uyarra, E. (2015) Universities and KIBS as sources of knowledge for innovative firms in peripheral regions, Regional Studies, 49(11): $1873-1891$.

Simmie, J., and Martin, R.L. (2010) The economic resilience of regions: towards an evolutionary approach, Cambridge Journal of Regions, Economy and Society, 3: 27-43.

Ter Wal, A., and Boschma, R. (2008) Applying social network analysis in economic geography: framing some key analytic issues, The Annals of Regional Science, 43(3): 739-756. 
Tüzin Baycan and Hugo Pinto - 9781786432193 Downloaded from PubFactory at 04/26/2023 12:41:49PM 